Abstracta Iranica Abstracta Iranica

Revue bibliographique pour le domaine irano-aryen

Volume 28 | 2007

Comptes rendus des publications de 2005

\title{
A survey of the Geography of Iran. Tehran, Center for International Cultural studies, 2003, 107 p. (The Book of Iran)
}

Bernard Hourcade

\section{(2) OpenEdition}

Journals

Édition électronique

URL : http://journals.openedition.org/abstractairanica/11242

DOI : 10.4000/abstractairanica. 11242

ISSN : 1961-960X

Éditeur :

CNRS (UMR 7528 Mondes iraniens et indiens), Éditions de l'IFRI

Édition imprimée

Date de publication : 15 mai 2007

ISSN : 0240-8910

Référence électronique

Bernard Hourcade, " A survey of the Geography of Iran. Tehran, Center for International Cultural studies, 2003, 107 p. (The Book of Iran) », Abstracta Iranica [En ligne], Volume 28 | 2007, document 489, mis en ligne le 18 septembre 2007, consulté le 25 septembre 2020. URL : http://journals.openedition.org/ abstractairanica/11242; DOI : https://doi.org/10.4000/abstractairanica. 11242

Ce document a été généré automatiquement le 25 septembre 2020.

Tous droits réservés 


\section{A survey of the Geography of Iran. Tehran, Center for International Cultural studies, 2003, 107 p. (The Book of Iran)}

\section{Bernard Hourcade}

Ce manuel de présentation géographique de l'Iran est publié en anglais à Téhéran dans la collection «The Book of Iran » couvrant toute l'histoire, les sciences sociales, et la culture iraniennes. L'Iran est présenté de façon analytique et très brève (géologie, relief, climat, végétation, zoologie, population, villes, villages, tribus) à partir de sources iraniennes. Cet ouvrage d'initiation ne comprend hélas aucune carte.

\section{INDEX}

Thèmes : 15.1. Iran

\section{AUTEURS}

BERNARD HOURCADE

CNRS / Mondes iranien et indien - Paris 